\title{
El yacimiento arqueológico de Los Bañales (Uncastillo, Zaragoza): ensayo de actualización
}

\author{
The archaeological site of «Los Bañales» \\ (Uncastillo, Zaragoza): essay of revision
}

\author{
María Dolores Lasuén Alegre \\ EUGENIA NASARRE Otín \\ Proyectarte/Fundación Uncastillo
}

\begin{abstract}
RESUMEN
Los Bañales es una ciudad romana con sustrato indígena ubicada en un área de intensa romanización en el Valle Medio del Ebro, en la Tarraconensis, y que, entre sus muchas peculiaridades, presenta un sistema de abastecimiento y de aprovechamiento hidráulico con acueducto conservado notablemente singular. El estudio que aquí se presenta - que plantea una revisión arqueológica del conjunto-surge como parte de los trabajos preliminares de puesta en valor del yacimiento y de su Plan de Investigación.
\end{abstract}

\section{PALABRAS CLAVE}

Los Bañales, ingeniería hidráulica romana, poblamiento, termas romanas, acueducto.

\section{ABSTRACT}

Los Bañales is a Roman city with indigenous substract, situated in a very intense romanized area in the middle of the Ebro Valley, in Taraconensis province. Between its important singularities, it also presents a supply and hydric use system with a very singular thermae and aqueduct system. This study - that tryes to do a review of the archeological site-comes out as part of a previous and current research-work, related to the rehabilitation of the archaeological site and with its current Researching Plan.

\section{KEYWORDS}

Los Bañales, Roman Hidraulic Engineering, Roman Settlement, Roman Thermae, Roman Aqueducts. 


\section{CONTEXTO GEOGRÁFICO'}

Los Bañales es un yacimiento arqueológico situado en el término municipal de Uncastillo, provincia de Zaragoza. Se encuentra a pocos kilómetros al Norte del municipio de Layana, al Sudeste de la carretera que une Sádaba con Uncastillo, en el valle del río Riguel y en las últimas estribaciones del Prepirineo dentro de la comarca de las Altas Cinco Villas.

Es un enclave localizado en uno de los caminos secundarios que se desarrollan en torno a la cuenca fluvial del río Arba con sus afluentes: Agonías, Arba de Biel, Arba de Luesia y Riguel; vías naturales que confluyen en las inmediaciones de Ejea de Los Caballeros. Geológicamente, la zona se define como una gran llanura de glacis-terrazas, con inclinación Noreste-Sudoeste ${ }^{2}$.

En concreto el yacimiento se ubica en un área que engloba un diámetro de $4 \mathrm{ki}-$ lómetros, emplazados en su mayor parte en la depresión conocida como Val de Bañales, y enmarcada por el Pueyo de Los Bañales en su límite Este y por el dominio de Puy Foradado en su margen Noroeste, con un pequeño cerro marcando el límite Sur con restos arqueológicos en su cima conocidos como La Rueca y el Huso.

Val de Bañales está situado sobre un terciario continental del Mioceno 1, con materiales constituidos por areniscas, arcillas, margas, calizas y yesos. Según M. Cisneros ${ }^{3}$, se corresponden en parte con la formación de Uncastillo, con un sistema de cuñas de areniscas conglomeráticas alternadas con margas que se pierden hacia la Depresión del Ebro. La altura media es de 450 metros, con el punto más alto localizado en el Pueyo de Los Bañales con 561 metros sobre nivel del mar. La pendiente media de la zona es del $1,3 \%$.

El tipo de explotación actual del espacio se centra básicamente en el cultivo de secano dado el escaso régimen pluviométrico y la poca conservación de humedad a nivel de superficie. La vegetación virgen está compuesta por matorral mediteráneo, típico de un área como la que el yacimiento ocupa, con clima continental.

\section{CONTEXTO HISTÓRICO ARQUEOLÓGICO}

Los Bañales es un ciudad situada geográficamente a medio camino entre Pompaelo y Salduie/Caesaraugusta, y cuyos restos arqueológicos son casi en su totalidad de época romana. Se trata de un asentamiento desarrollado en llano, relativa-

\footnotetext{
1 El presente trabajo se integra en las actividades del Anteproyecto de Plan de Investigación que -bajo la autorización, financiación y encargo de la Dirección General de Patrimonio Cultural del Departamento de Educación, Cultura y Deporte del Gobierno de Aragón y el apoyo de la Fundación Uncastillo- se viene llevando a cabo en el citado yacimiento. El trabajo se ha visto notablemente enriquecido por los comentarios aportados por los informantes anónimos de la revista Espacio, Tiempo y Forma a quienes queremos dejar constancia de nuestra gratitud. Lógicamente, los errores u omisiones presentes en el texto son responsabilidad única y exclusiva de los firmantes del mismo.

2 LABE, L. F.: 1975, 831-835.

3 CISNEROS, M.: 1986, 614.
} 
mente alejado del abastecimiento de recursos hídricos, sin amurallamiento conocido, y con - a nuestro juicio - una alta probabilidad de poseer un sustrato de asentamiento previo indígena en El Pueyo de Los Bañales, cerro que se ubica dentro del área a estudiar, a 100 metros al Este del área monumental de la ciudad romana.

El documentado hallazgo de cerámica de tradición hallstática a torno ${ }^{4}$, relacionada con la zona habitacional más elevada del yacimiento, podría ser indicio de un primer asentamiento indígena de filiación celtibérica fechado entre los siglos IVIII a.C., si bien, necesariamente, la noticia deberá ser matizada con futuras actuaciones arqueológicas.

Un segundo momento cronológico vendría dado por un mínimo de restos de Campaniense $A$ en superficie ubicados en la misma área, y que nos remitirían al período de conquista romana del siglo II a.C., desde la Segunda Guerra Púnica hasta el fin de las guerras celtibéricas y el proceso pacificador. Según se constata habitualmente, en este contexto cronológico de fines del siglo II a.C. asistimos a una planificación urbanizadora por parte de $\mathrm{Roma}^{5}$ con el establecimiento de nuevas fundaciones, especialmente en el Nordeste peninsular, fenómeno que tiene un posterior auge con César, Augusto y Tiberio.

Estas primeras fundaciones se caracterizan por ser asentamientos en llano de alrededor de 20/10 Has., con carácter de centro económico y de control territorial/administrativo para áreas de explotación agrícola o minera ${ }^{6}$. La población de dichos centros estaría constituida por élites indígenas romanizadas, veteranos de guerra y, durante los primeros procesos fundacionales, también itálicos. Así, encontramos una gran profusión de estos nuevos modelos poblacionales en la Ribera del Ebro, con ejemplos en La Cabañeta del Burgo de Ebro, Celsa, Salduie, Contrebia Belaisca, etc. Podría pues pensarse que Los Bañales, dadas sus características geográficas, podría haber tenido una primera ocupación romana enmarcada en este contexto, a falta de fuentes arqueológicas que lo confirmen.

Un segundo momento urbanizador se da, como hemos reseñado, con Augusto y Tiberio, (del 44 a.C. al 31 d.C.), dando lugar a una reestructuración territorial con la constitución de la provincia Tarraconensis hacia el año 27 a.C. Es entonces cuando observamos un avance del fenómeno urbanizador en la margen derecha del Ebro al continuar la pacificación hacia el Oeste de la provincia. De esta forma aparecen nuevas fundaciones con estatuto de «colonia», siempre en encrucijadas naturales o zonas elevadas. Asistimos también a la fundación de Caesaraugusta en el 15 a.C., lo que da lugar a la reorganización de la zona con un nuevo modelo administrativo de contributio, con ciudades con función de coordinar los poblamientos indígenas cercanos. En este contexto, se asiste a la monumen-

${ }^{4}$ AGUAROD, C.: 1975, 988, trabajo realizado sobre el material de arrastre proveniente del poblado emplazado en lo alto del Pueyo de Los Bañales y que fuera hallado en las termas de Los Bañales durante las excavaciones dirigidas por A. Beltrán en 1972; noticia después recogida por BELTRÁN LLORIS, M.: 1990, Fig. 5.

5 Como es sabido, a través de Livio (Liv., 34, 21 y 39, 42) se documenta la presencia de Catón en la zona desde el 195 a.C. con acciones militares contra los Suessetanos.

6 CABALLERO, C. J.: 2003, 83. 
talización y reorganización urbana de ciudades como Bilbilis, Labitolosa, Ercavica, Clunia, etc. Sin embargo, muchas otras ciudades nacidas en el primer momento urbanizador del siglo II a.C. desaparecen, sobreviviendo sobre todo aquéllas ligadas a redes viarias que en este momento adquieren carácter de mansio ${ }^{7}$.

Las ciudades ahora tienen una clara finalidad de imposición del sistema económico y administrativo del Imperio ${ }^{8}$, permitiendo al indígena asimilar y reproducir las estructuras romanas, buscando un desarrollo agrario del territorio conquistado que pase por la comercialización de sus productos. Por ello, cobra entonces importancia la cercanía a redes viarias; las ciudades crecen en llano y hay ausencia de elementos significativos como murallas. La romanización está en fase avanzada, y la población local encuentra en lo «romano» un elemento de prestigio social.

En este contexto, Los Bañales halla también un marco histórico en el que fundamentar un posible momento habitacional, destacando su carácter de centro de territorio agrícola y sobre todo viario, aunando población local con emigración proveniente del resto del Imperio. Esto se vería apoyado por la aparición de terra sigillata sudgálica, y de la forma XXIV Mayet de paredes finas, que podrían contextualizar el yacimiento ya en el periodo julio-claudio, siempre a falta de confirmación a través de un nuevo - y necesario- estudio de sus restos arqueológicos y de una nueva - y ya proyectada - revisión del material arqueológico que, procedente de las excavaciones llevadas a cabo hasta la fecha en el lugar, se conserva en los fondos del Museo de Zaragoza.

Durante la primera mitad del siglo I d.C. nace un fenómeno que tendrá su auge en época Flavia, encontrando su mayor esplendor en el siglo III, incluso en el IV d.C. Nos referimos a la aparición de las villae como centros de producción agraria básicos ${ }^{9}$, que - para el Valle Medio del Ebro-C. J. Caballero ${ }^{10}$ articula en torno a la ciudad como fenómeno intrínseco a la estructuración territorial a través de ciuitas, siguiendo el modelo de ordenación del territorio implantado por Roma en todo el Imperio ${ }^{11}$. Así, la villa debe emplazarse en un radio de 5-10 km. en torno a

\footnotetext{
7 Podemos deducir de lo expuesto anteriormente que el origen de la ciudad romana de Los Bañales realmente se encuentra ligado a la existencia de un red viaria en la zona; seguramente habría una primera articulación del territorio en torno a la vía que uniría Caesaraugusta y Pompaelo; a esto se sumarían vías secundarías hacia la Vía Lata, (Osca-Pompaelo), y hacia la calzada que uniría Tarraco con Asturica. Así pues, Los Bañales tendría acceso por rutas comerciales a las principales ciudades del conuentus Caesaraugustanus, como ya apuntó GALIAY, J.: 1944, 21-23 a partir de los dos miliarios de Sádaba de época tiberiana; y del miliario de Castiliscar que fecha hacia el 213, bajo el gobierno de Caracalla, argumento después recordado por BELTRÁN MARTíNEZ, A.: 1977, 92; y por ORTIZ, E., y PAZ, J.: 2005, 20-21. Mientras se escriben estas líneas, un Plan de Investigación auspiciado por la Asociación para el Fomento de las Cinco Villas-ADEFO y liderado por el ingeniero I. Moreno, ultima un trabajo de revisión del trazado de la vía Caesaraugusta-Pompelo antes anotada.

8 Vestigios de una posible centuriación en el área de estudio los documenta LABE, L. F.: 1975, 831-835.

9 BELTRÁN LLORIS, F.: 1976, 155-160.

10 CABALLERO, C. J.: 2003, 84. Las villae aparecen según el autor a raíz de la implantación de la ciudad, en el momento en que la población indígena asimila la estructura económica romana y la pacificación permite la explotación de la zona. Por ello las villae se articulan de forma concéntrica al centro urbano.

11 BENDALA, M., y ABAD, L.: 2008 y para dicho proceso en el Ebro Medio el trabajo reciente de BELTRÁN LLORIS, M.: 2007.
} 
una ciudad y con proximidad a una red viaria, desarrollándose muchas veces a lo largo de ésta; así, éstas se convierten en un ejemplo de proyección de la ciudad hacia el campo.

Dentro de este fenómeno de explotación del campo a través de asentamientos agropecuarios tipo villae, observamos en un perímetro de 5 kilómetros en torno a Los Bañales (Fig. 1) un buen número de éstos ${ }^{12}$ dedicados supuestamente al cultivo de trigo y que justificarían, si no el origen, sí la pervivencia de la ciudad a lo largo de época imperial como centro económico y de difusión de la producción agraria de la zona, siguiendo la descripción trazada por F. Beltrán ${ }^{13}$. Así, el origen de Los Bañales sería independiente y anterior a la aparición de este fenómeno articulador del campo, pero sin duda la pervivencia de la ciudad no se explica sin él.

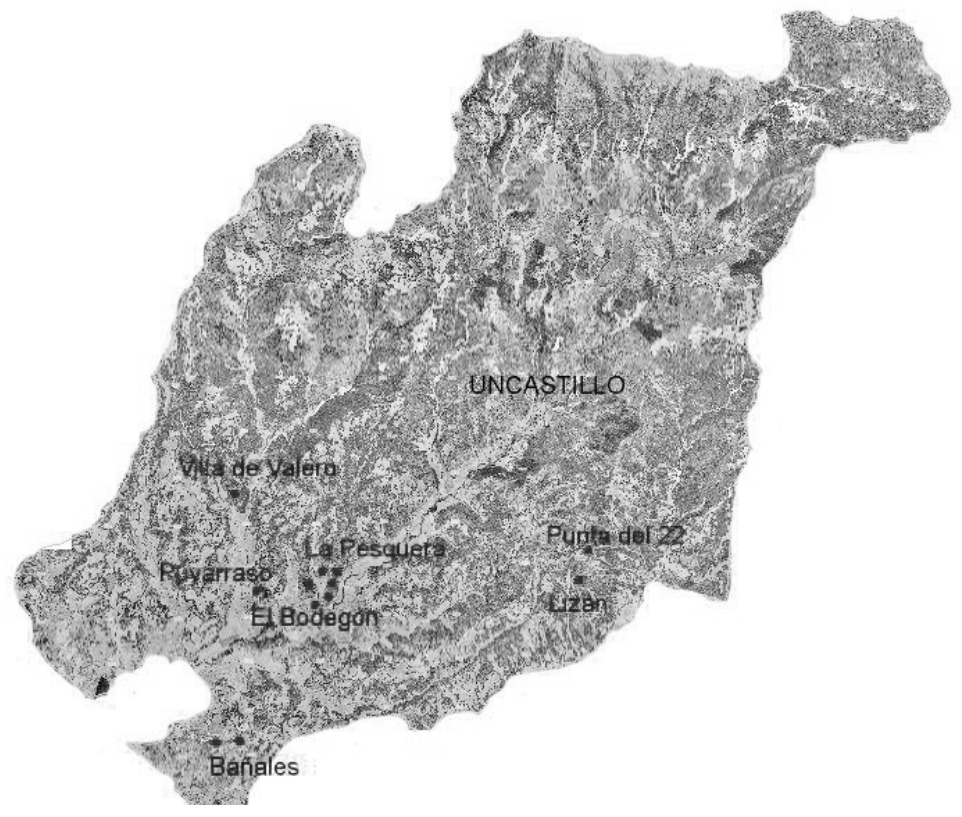

Fig. 1. Distribución de las villae en el entorno del yacimiento de Los Bañales.

12 BELTRÁN LLORIS, F.: 1976, 157-158, nombra las siguientes villae: Corral de Valero, Castiliscar; Corral de Puyarraso, al Oeste de El Pueyo Los Bañales; la Rueca y el Huso, al Sur del yacimiento; villa sin descripción a 150 metros al Suroeste de Puy Foradado; Cerro Puyalmanar; Villa de los Atilios, junto al Mausoleo de los Atilios, única estudiada y descrita de forma monográfica por GARCÍA Y BELLIDO, A.: 1963. Por su parte, GALIAY, J.: 1944, 8, hace una serie de referencias extremadamente vagas a este respecto. Añadimos a este respecto existencia de una cupa labrada de época romana hallada en el término municipal de Uncastillo, en posesión de un particular publicada por ANDREU, J., JORDÁN, Á., NASARRE, E., y LASUÉN, M. (en prensa). Prospecciones recientes del término municipal de Uncastillo, y realizadas dentro del Plan de Ordenación Urbana de la villa, confirman la existencia de villas romanas en el área de El Bodegón, Puyarraso, La Bueta, Los Atilios, Corral de Valero, y La Pesquera (LASUÉN, M. ${ }^{a}$ D., y NASARRE, E.: 2008).

13 BELTRÁN LLORIS, F.: 1976, 155-160. 
La ciudad en el siglo I d.C. adquiere una mayor complejidad en su estructura urbana con una diversificación de funciones entre las que se cuenta la administrativa, religiosa, la de centro de producción agrícola y de distribución y comercialización, la de cruce de caminos, la de zona de confluencia social, etc. Por ello, ya en época Flavia, con el auge económico del Occidente del Imperio, se da una segunda fase de reorganización y monumentalización en los centros urbanos, como podemos observar en Tarraco, Bilbilis, Caesaraugusta, Valeria, etc ${ }^{14}$. Como se ha propuesto por J. Andreu y Á. A. Jordán, la presencia de una Quirina tribus en el Mausoleo de los Atilios ${ }^{15}$ evidencia la más que probable promoción a municipio flavio del enclave.

Dentro de este proceso, datado por la gran multitud de fragmentos de terra sigillata Hispanica y terra Sigillata clara A y B, y ánforas Dressel 28 conservados, se enmarcarían las obras monumentales de Los Bañales: las de abastecimiento de agua (la presa, el acueducto, las termas, y posiblemente las cisternas, a falta de conocer el castellum aquae); y las obras de monumentalización de los espacios públicos de la ciudad: el supuesto foro, un posible templo, el arco de triunfo...

La pervivencia de la ciudad en el siglo III y IV d.C. vendría apoyada por el hallazgo de restos de lucernas datados por C. Aguarod ${ }^{16}$ entre el 225 y el 350 d.C. A su vez, la cercanía del Mausoleo de La Sinagoga, del siglo IV d.C. ${ }^{17}$, y de las viIlae adyacentes a Bañales, nos hablan de la existencia de poblamiento notable en este periodo. Así, el declive de la ciudad podría enmarcarse dentro del proceso de crisis económica general del siglo III, pudiendo fecharse su abandono de forma aproximada con la tardoantigüedad, a falta de un estudio exhaustivo de este aspecto del hábitat de la ciudad, y basándonos exclusivamente en la ausencia de materiales conocidos de época posterior.

\section{EL YACIMIENTO DE LOS BAÑALES: ESTUDIO DOCUMENTAL}

\subsection{Fuentes literarias y toponímicas}

Los Bañales, a falta de un estudio exhaustivo y en profundidad del yacimiento y del proceso romanizador de las Altas Cinco Villas, parece ser, como ya hemos expuesto, una ciudad fundada en un entorno de explotación agrícola al amparo de la red viaria romana. A este respecto existen diversas hipótesis que, a partir de la arqueología de la zona y del estudio de las fuentes, especialmente del Itinerario de Antonino ${ }^{18}$, tratan de realizar una aproximación al topónimo original de la ciudad.

${ }^{14}$ Con bibliografía en ANDREU, J.: 2004 y en los distintos casos documentados en RAMALLO, S.: 2003.

${ }^{15}$ ANDREU, J., y JORDÁN, Á. A.: 2003-2004, 448, n. ${ }^{\circ} 13$ a partir de CIL, II, 2973, n. ${ }^{\text {s }} 13-15$.

16 AGUAROD, C.: 1975, 988.

17 GARCÍA Y BELLIDO, A.: 1963; GORGES, 1979, 351. Más recientemente, sobre el balneum de la uilla, GARCÍA-ENTERO, V.: 2001, 277-279 y, sobre el mausoleo PALOL, P. DE: 1967, 132-126.

18 CABALLERO, C. J.: 2003, 115-116, en cualquier caso, matiza el uso indiscriminado del Itinerario de Antonino como fuente documental, ya que no lo considera un reflejo real del proceso urbanizador de la romanización, al estar condicionado por errores de autor, transcriptores, interpretación, etc. 
La teoría más antigua la elabora J. Galiay ${ }^{19}$, ubicando Los Bañales en la vía militar que unía Tarraco con Asturica Augusta en enlace directo a través del Mausoleo de los Atilios. Otra posible conexión la establece con la llamada vía Lata, entre Osca y Pompaelo. Así, encontraríamos Los Bañales una vez cruzado el río Gállego, antes de llegar al Mausoleo de los Atilios. En ambos casos, siguiendo el Itinerario de Antonino, identifica la ciudad con la mansio Clarina.

Por su parte, en estudios posteriores $\mathrm{A}$. Beltrán ${ }^{20}$ hace referencia a la relación directa de la ubicación de Los Bañales con la existencia de una red viaria de cierta entidad en sus inmediaciones, descartando Clarina como topónimo de la ciudad. De esta forma establece un nuevo recorrido en el cual Los Bañales se encontraría a 128 millas de Caesaraugusta, según el Itinerario Antonino, correspondiéndose con la ciudad de Atiliana, hecho corroborado arqueológicamente según A. Beltrán por la cercanía al Mausoleo de los Atilios.

La teoría más actual acerca de la ubicación de Los Bañales en el entramado de la red viaria romana de la zona es la esbozada por M. ${ }^{a} \mathrm{C}$. Aguarod y J. Lostal21, que identifican el yacimiento con la ciudad de Tarraca, basándose en fuentes literarias y arqueológicas que la situarían en el itinerario de la vía de las Cinco Villas que unía Caesaraugusta con Pompaelo, pasando por Segia y Cara.

Así pues, a día de hoy nos encontramos ante un problema de intepretación de fuentes escritas y arqueológicas, al que se suma un vacío en el conocimiento exacto de las redes viarias de la zona, que impiden una identificación fiable del topónimo real del yacimiento. Por ello, a falta de ulteriores estudios, dejamos la cuestión de la identificación del yacimiento abierta, lo que, como puede comprenderse, limita a su vez el estudio del yacimiento a través de fuentes literarias clásicas.

Como fuentes literarias modernas, contamos con dos testimonios. El primero es el del cosmógrafo portugués J. B. Labaña ${ }^{22}$, que en 1610 describe la ciudad de Los Bañales, a la que identifica con Clarina, y que realiza una serie de croquis y mediciones de las edificaciones más importantes del yacimiento. Así, gracias a él conocemos el aspecto de las columnas del históricamente llamado «foro» de los pilares del acueducto, de las termas (que identifica erróneamente con «la Casa»), y, sobre todo, del desaparecido arco de triunfo. Por otra parte, Labaña cita treinta y seis pilares en el acueducto, frente a los treinta y dos actualmente conservados.

La siguiente mención a Los Bañales la realiza el cronista J. Zurita ${ }^{23}$, quien identifica el yacimiento con la ciudad de Atiliana basándose en la cercanía al Mausoleo de los Atilios. El resto de referencias que encontramos se deben a interpretaciones posteriores de los textos de estos dos autores pero sin conocimiento directo del yacimiento, por lo que no las tomamos en consideración.

\footnotetext{
19 GALIAY, J.: 1944, 21-23, como ya anotamos más arriba (véase nota 7).

20 BELTRÁN MARTÍNEZ, A.: 1977, 94.

21 AGUAROD, C., y LOSTAL, J.: 1982, 167-218.

22 LABAÑA, J. B.: 1895, 16 y 18-19.

23 Recogida por BELTRÁN MARTíNEZ, A.: 1977, 92.
} 
El otro elemento que utilizamos en el estudio previo del yacimiento son las fuentes toponímicas que han llegado hasta nuestros días, bien por tradición oral, bien a través de textos modernos.

Así, los mismos sustantivos de Bañales, Val de Bañales, o Pueyo de Los Bañales, nos remiten a la palabra latina balneum ${ }^{24}$, indicándonos de forma directa el conocimiento exacto en la zona de la existencia y funcionalidad de las termas, y a la vez dando una idea del área geográfica que abarca el yacimiento.

Otro sustantivo relacionado con la zona es el de «Los Pilares», que nombra así los restos de la arquitectura vertical conservada del acueducto que atraviesa el yacimiento.

El topónimo quizá más interesante del yacimiento sea el de Puy Foradado, nombre con el que se conoce el cerro enfrentado hacia el Este con el Pueyo de los Bañales, y hacia el que se dirige el trazado del acueducto. Así, Foradado vendría a ser «horadado ${ }^{25}$ », en clara referencia directa al specus del acueducto que bordearía o atravesaría el cerro para unir la caput aquae de aquél con el valle donde se asienta la ciudad romana.

Ligeramente alejado de la zona encontramos el Puente del Diablo, que señala una presa para captación de aguas construida en el río Arba de Luesia, término municipal de Biota ${ }^{26}$, y cuyo nombre concuerda con el topónimo del acueducto del Barranco de las Ferreras, en Tarragona ${ }^{27}$, dando continuidad a la tradición de atribuir al diablo la realización de obras de gran envergadura anteriores a poblaciones medievales y modernas. En cualquier caso, a día de hoy no existe consenso acerca de la relación de esta obra de contención en el río Arba con Los Bañales.

\subsection{Intervenciones arqueológicas}

La primera intervención arqueológica sistemática en Los Bañales corrió a cargo de J. Galiay, en 1942/43, siendo publicados los resultados en $1944^{28}$, con una segunda fase de excavación entre 1946 y 1947, que se publica en 194929. Durante la primera intervención J. Galiay realizó una primera prospección visual que comprendió el terreno ubicado entre Puy Foradado y el cerro que acoge los restos de La Rueca y el Huso, que identificó erróneamente con elementos megalíticos.

Llevó a cabo otra prospección en el mismo año en el Pueyo de Los Bañales, buscando los accesos al poblado que se encuentra en lo alto del cerro, siendo

${ }^{24}$ Es normal que zonas relacionadas con estructuras hidráulicas toponímicamente provengan de balineum, o balneum, pudiendo ser sus nombres Baños, Bath, etc., como ha demostrado DIEZ DE VELASCO, F.: 1998, 35-37.

25 Según interpretación de GALIAY, J.: 1944, 9.

26 BELTRÁN MARTÍNEZ, A.: 1977, 95.

27 ARENILLAS, M.: 2002.

28 GALIAY, J.: 1944.

29 GALIAY, J.: 1949. 
vago en sus descripciones por lo que no conocemos el alcance real de estos trabajos. Sin embargo, en 1943 realizó una primera descripción de los principales elementos del yacimiento: acueducto, presa, termas, zona del foro, que identificó erróneamente con un templo, y el poblado.

Así, describe el sistema hidráulico de la ciudad localizando la caput aquae en el Arba de Luesia, a la altura del Puente del Diablo en término municipal de Malpica de Arba, donde nombra una primera presa o muro de contención. A su vez ya da referencias de la presa que se encuentra al Este de Puy Foradado, con una sucinta descripción de la misma.

Según él, la conducción del agua hasta la ciudad se realizaría a través del acueducto, que describe resaltando el trazado en curva, hecho que J. Galiay atribuye a un caudal escaso canalizado en conductos de madera o cerámica, y a la topografía. Calcula 300 metros de acueducto elevado con cerca de setenta y cinco pilares, de los cuales documenta treinta y dos. Es interesante cómo observa los restos de trabajos de cantería para la realización del acueducto en la misma roca sobre la que se asientan los pilares. También describe dos tipos de specus a nivel de tierra: en cauce natural y en cauce labrado en roca. Considera que ambas conducciones estarían cubiertas, con cámaras de ventilación a lo largo del recorrido. Este acueducto desembocaría en el aljibe que se encuentra junto al lienzo Este de la Ermita de Nuestra señora de Los Bañales para uso industrial o agrícola y de abastecimiento a las termas.

El estudio pormenorizado del recinto termal lo realiza J. Galiay en su segunda campaña, destacando la referencia a ricos revestimientos y decoración moldurada. En ella determina la existencia de tres estancias principales: el apodyterium, con la bóveda de cañón parcialmente en pie; seguido de dos espacios hoy identificados como frigidarium y tepidarium, que excava sólo en parte debido a los restos de derrumbe del lienzo Sur del apodyterium. Estos dos espacios los considera en principio uno sólo, y sin cubiertas.

Excava hasta los niveles de cimentación del edificio dejando al descubierto un pasillo de servicio con una canalización bajo pavimento que rodea las termas por el Este, y que Galiay enlaza hipotéticamente con la cisterna ubicada en la Ermita; y la sala de espera del edificio, que identifica erróneamente con el caldarium o la sudatio. Documenta, además, restos de pavimento con opus spicatum en el apodyterium y el tepidarium mediante sondeos en la zona Oeste del edificio. Del mismo modo, observa el hueco existente entre la pared del apodyterium y la del espacio que denomina B (hoy conocido como caldarium).

Por su parte, en la zona del Foro, documenta las dos columnas ya vistas por J. B. Labaña en 1610, describiendo las cimentaciones de la zona y atribuyéndoles una errónea datación posterior a Roma.

En lo referente al Poblado del cerro de El Pueyo de Los Bañales, J. Galiay lleva a cabo una serie de prospecciones, desbroces y sondeos en busca del acceso al mismo, y realiza una pequeña excavación en algunas de sus casas documen- 
tando restos de cerámica indígena. En base a esto data el poblado como Ibérico, adscrito a la «Cultura Pirenaica de la Edad del Bronce ${ }^{30}$ ».

Tras las actuaciones de J. Galiay debemos esperar hasta las excavaciones continuadas de A. Beltrán con un equipo de la Universidad de Zaragoza, desarrolladas entre 1972 y 1975, cuyos resultados se exponen a través de diversas publicaciones ${ }^{31}$.

La intervención de A. Beltrán se centra especialmente en dos aspectos de la ciudad: una revisión del poblado del cerro de El Pueyo de Los Bañales mediante la realización de sondeos a fin de establecer una cronología y estratigrafía para el mismo; y un análisis del sistema hidráulico de abastecimiento de la ciudad, haciendo especial hincapié en el uso de dicha agua a través de una ampliación de las excavaciones realizadas más de veinte años antes por J. Galiay.

En lo referente al poblado sobresale la datación propuesta por A. Beltrán, considerando más posible un origen del asentamiento en época romana que en la etapa celtibérica ${ }^{32}$, desechando así la tesis de J. Galiay de un posible desarrollo inicial indígena ${ }^{33}$.

El poblado es descrito como un hábitat articulado en dos niveles de aterrazamiento junto con la zona superior del cerro, donde ubica una estructura noble cimentada en parte en la roca. Seguiría a ella un primer nivel de terraza con casas en disposición radial y restos de un posible amurallamiento en la fachada Sur, junto a un espacio abierto en la zona Norte. La segunda terraza, ya excavada por J. Galiay, la conforma un grupo de casas estructuradas por manzanas y calles escuadradas en ángulo recto, con elementos más ricos que en el resto del poblado. Los materiales hallados tienen en su mayor parte cronología romana, destacando unos pocos restos de Campaniense $A$ en la parte superior del cerro.

La unión del poblado con la ladera y el valle se realizaría a través de una calle de acceso con restos de enlosado que bajaría desde la primera terraza, retranqueando al llegar a la segunda, lo que implica un cambio de orientación donde A. Beltrán propone la existencia de una puerta. De ahí se enlazaría con el arco de triunfo descrito por J. B. Labaña, y que según A. Beltrán se ubicaría en una de las entradas laterales de la Ermita.

A. Beltrán también desbroza y limpia los elementos monumentales que quedan a la vista, desestimando la identificación del espacio del Foro con el de templo he-

30 GALIAY, J.: 1949, 30.

${ }^{31}$ AGUAROD, C. 1975; BELTRÁN MARTíNEZ, A: 1975; BELTRÁN MARTíNEZ, A: 1977; BELTRÁN LLORIS, F.: 1975 y 1976.

${ }^{32}$ Del mismo modo desestima la datación megalítica para La Rueca y el Huso hecha por GALIAY, J. 1949, 19-20; y lo enmarca dentro de un horizonte cronológico de época romana, seguido también por BELTRÁN LLORIS, F.: 1975, 1056.

${ }_{33}$ Para ello lleva a cabo dos sondeos, uno en la zona de poblado no excavada todavía, y otro en la casa A-1, siguiendo la nomenclatura de GALIAY, J.: 1944, 24. Aquí encuentra materiales de adscripción romana y documenta la factura de los muros, llegando a la conclusión de que el material hallado por Galiay no es base suficiente para establecer un origen en sustrato celtibérico (BELTRÁN LLORIS, F.: 1975, 1060). 
cha por J. Galiay. Así, ubica una calle con aceras y casas adyacentes junto al Foro y -a partir de los materiales- data el apogeo de éste ${ }^{34}$ en el siglo II d.C., manteniéndose en uso al menos hasta el siglo III.

En cuanto al sistema de abastecimiento hidráulico de la ciudad, A. Beltrán hace un estudio preliminar de fuentes ${ }^{35}$, y realiza una exploración del total del acueducto. Establece la caput aquae en la presa que se encuentra al Este de Puy Foradado donde ubica, basándose en noticias orales de vecinos de la zona, un manantial hoy extinto ${ }^{36}$.

Desde ahí sólo encuentra lo que identifica como canales de derivación de agua hasta llegar a Puy Foradado. En el cerro no observa restos del specus, planteando su posible paso a Val de Bañales a través del collado lateral de la ladera Norte, continuando la canalización con el trazado de pilares. A. Beltrán documenta los treinta y dos pilares actuales, dividiéndolos para su estudio en cuatro tramos ${ }^{37}$. Continúa documentando el specus ya en canalización a nivel de superficie y excavado en roca, hasta llegar a la zona monumental donde propone su almacenamiento en dos compartimentos: la cisterna que se encuentra al Este de la Ermita; y una segunda cisterna en una cota inmediatamente superior a las termas, al Norte de éstas. Desde ahí el agua llegaría a las termas a través de canalizaciones por medio de tubuli cerámicos. Según él a lo largo de todo el recorrido se observan restos de asentamientos rurales ${ }^{38}$.

El principal problema que plantea A. Beltrán en el recorrido del acueducto es el desnivel existente entre el specus y el acceso a la cisterna situada junto a la Ermita, que implicaría el uso de un sifón para salvarlo. Otro problema es la ubicación del castellum aquae, hasta hoy desconocida. Además, propone el uso de sistemas de almacenamiento de aguas pluviale ${ }^{39}$ como complemento al abastecimiento del acueducto, justificando esta hipótesis con las numerosas cisternas halladas en el yacimiento.

La construcción del acueducto la fecha en torno al siglo I, inicios del II, considerándolo como elemento dependiente de la construcción, funcionamiento y uso de las termas.

Es en el conjunto termal en el que A. Beltrán centra la mayor parte de su actuación, llevando a cabo la documentación y estudio de las estructuras ya mos-

${ }^{34}$ BELTRÁN LLORIS, F.: 1976, 162.

35 Consulta los informes anteriores de J. B. Labaña y de J. Galiay, y toma en cuenta a J. R. Mélida y a J. L. Jiménez (BELTRÁN MARTÍNEZ, A.: 1977, 95).

${ }^{36}$ Así, desestima la interpretación de J. Galiay, que establecía la toma de agua en el Arba de Luesia a la altura de Malpica de Arba, en el Puente del Diablo (BELTRÁN MARTíNEZ, A.: 1977, 96).

${ }^{37}$ Así, BELTRÁN MARTíNEZ, A.: 1977, 97 calcula que faltan alrededor de treinta pilares, unos 150 metros de acueducto elevado y considera que el acueducto se adapta a la topografía y que no sigue las normas estilísticas de Roma.

${ }^{38}$ Estos asentamientos, posibles villae muestran una cronología en sus restos más amplia que en el poblado, con Campaniense B, C, y terra sigillata hispánica y gálica hallada en superfice, según BELTRÁN MARTÍNEZ, A. 1977, 128.

${ }^{39}$ Observa paralelismos en este sentido en Bilbilis, Valeria, Contrebia..., y en el Norte de África (BELTRÁN MARTÍNEZ, A.: 1977, 94). 
tradas por J. Galiay y ampliando las excavaciones hacia el Sur y el Oeste del apodyterium. Se llevan a cabo las obras de restauración y reconstrucción de las termas $^{40}$ a la vez que los consabidos trabajos arqueológicos.

Así, A. Beltrán realiza la limpieza y desescombro del material acumulado en las excavaciones de Galiay, que afecta a la zona Norte de acceso a las termas. Estudia y documenta el vestíbulo de acceso a la sala de espera; ésta misma con sus bancos adosados a los muros; y la bóveda que da paso al apodyterium.

Identifica el apodyterium, y termina de excavar las dos estancias gemelas que encuentra al Sur del mismo, levantando y reconstruyendo para ello el lienzo Sur del apodyterium que se había desplomado sobre las mismas. De esta forma se encuentra con dos estancias que identifica con un destrictorium para unciones; y con el tepidarium. Al Sur de las mismas documenta un espacio que considera el frigidarium, ubicando en el mismo las piscinae con el hallazgo de un tubo de plomo que enlaza el espacio con el canal de aguas perimetral al edificio.

Al Oeste del apodyterium identifica el caldarium en la estancia ya excavada en su día por J. Galiay, documentando los huecos en los muros para la colocación de tegulae mammatae. Observa en la zona Norte de la habitación un pavimento enlosado con seis orificios de apoyo, interpretando el espacio como el praefurnium del edificio, pudiendo servir los apoyos para sostener una caldera metálica que sirviera como horno calefactor. El hueco ya constatado por J. Galiay en el muro del caldarium y del apodyterium lo interpreta como el conducto de una chimenea.

Continúa los trabajos hacia el Oeste del caldarium, excavando hasta nivel de pavimento el espacio que identifica erróneamente como laconicum (como más adelante comentaremos, cfr. § 4.3). Al Norte del caldarium describe un acceso secundario al apodyterium por medio de un pasillo enlosado bajo el que discurre una canalización. Este pasillo da paso a una zona que A. Beltrán solamente limpia identificándola con la palestra, o zona al aire libre.

En cuanto a canalizaciones documenta el canal perimetral ya descrito por J. Galiay; el canal ubicado bajo el enlosado del pasillo entre el apodyterium y la palestra; y un canal al Norte del ya citado pasillo, en una cota superior, que recogería las aguas de las canalizaciones de los tejados del edificio y de la bóveda de acceso a las termas, conduciéndolas al interior de ellas a través de un orificio ubicado en uno de los loculi del apodyterium. Al Noreste del mismo, y también a nivel superior, A. Beltrán ubica una cisterna; aparte, plantea que conectasen mediante tubuli las termas con las cisternas abastecidas por el acueducto.

La observación más interesante planteada por A. Beltrán es la interpretación de los distintos vanos de acceso a los espacios. Calcula que gran parte de éstos están modificados debido a las reutilizaciones del edificio como viviendas, corrales y huertos, y se basa para estas afirmaciones en la cota de altura de los mismos. Tiene en cuenta que el nivel actual de pavimento de las estancias de tepidarium, cal-

40 Proyectadas por M. Almagro Gorbea, y realizadas por E. Tricás, según BELTRÁN MARTíNEZ, A.: 1977. 
darium y laconicum se encuentra 1,20 metros por debajo de la cota de pavimento original, lo que hace que los accesos que hoy día se encuentran a nivel de superficie sean de factura moderna, con el fin de facilitar el uso y comunicación de las diversas estancias.

En conclusión, el recorrido termal propuesto por A. Beltrán se iniciaría por el acceso a través del vestíbulo y la sala abóveda al apodyterium dejando atrás la sala de espera. De ahí se enlazaría por un lado con el destrictorium, y por otro a través del pasillo con la palestra. Desde el destrictorium, usado como sala de unciones y con una posible zona de letrinas, se pasaría al frigidarium con sus piscinae. Igualmente se podría acceder mediante una escalera, de la que A. Beltrán no observa restos, al tepidarium. Una vez en esta sala, el recorrido continuaría hacia el caldarium, y desde el mismo se accedería o bien al laconicum, o bien a la palestra. A. Beltrán considera, además, que el uso de las termas sería de carácter mixto, en distintos horarios para hombres o mujeres; y calcula un aforo de cerca de sesenta personas haciendo uso de las instalaciones de forma simultánea.

Tras las excavaciones de A. Beltrán se han llevado a cabo una serie de actuaciones dirigidas por J. M. Viladés en 1998 que han afectado a la zona perimetral del edificio termal. Esto es, se ha realizado una ampliación de las excavaciones en la zona Este desde el apodyterium hasta las piscinae, siguiendo la canalización perimetral de las termas y ampliando hacia el Este cerca de 3 metros, documentando unas estructuras murarias de una fase posterior. Otra ampliación ha continuado toda la fachada Sur de los restos, ampliando entre 5 y 10 metros la excavación de los años setenta, dividiéndose ahora el espacio de piscinae en dos espacios gemelos, como continuación del tepidarium y destrictorium de la propuesta A. Beltrán. Igualmente, al Sur del caldarium aparecen restos de más canalizaciones.

A su vez se ha excavado la camera sudatio hasta nivel de cimentación; así como el espacio identificado con la palestra por A. Beltrán, tanto al Este como al Norte del laconicum. Se han limpiado una serie de espacios divididos por columnas con restos de hypocaustum, un posible praefurnium al Este del laconicum, y diversas canalizaciones, alguna con la misma estructura que la hallada al Sur del laconicum, que enlazan estos nuevos espacios con el tepidarium y el propio laconicum.

\section{DESCRIPCIÓN DEL YACIMIENTO}

Para su estudio resulta lógico dividir el espacio arqueológico en dos áreas principales: la ciudad o zona de habitación, incluyendo en ella todo el sistema de abastecimiento hidráulico a través del acueducto; y el sistema de villae, que se articulan en torno a la ciudad y el specus.

En estas páginas vamos a describir la primera de las dos áreas, esto es, la ciudad y el sistema de abastecimiento de aguas. Así, observamos las siguientes zonas dentro de la misma, según su carácter funcional y social 


\subsection{El Poblado indígena y la Necrópolis}

Un primer espacio lo ocuparía el poblado indígena descrito por J. Galiay, documentación posteriormente ampliada por A. Beltrán. Sin modificaciones aparentes desde los años setenta, excepción hecha de la colocación de señalizaciones direccionales, nos encontramos ante los tres niveles descritos por A. Beltrán (cfr. $\S 3.2$ ), con una ocupación de las dos terrazas de la ladera de El Pueyo de Los Bañales y de la parte superior del cerro.

La zona más elevada es, pues, un área habitacional con restos de cimentación en roca ${ }^{41}$-fundamentalmente huecos de postes y cajas de cimentación-, junto con fosas que podrían ser de enterramiento excavadas en piedra. En la cota inmediatamente inferior y orientada al Este del yacimiento se desarrolla lo que parece ser el primer hábitat de El Pueyo. Nos encontramos ante un conjunto de casas con los muros conservados con un alzado mínimo, en los que se esboza una planta de poblado de casas en disposición radial, con accesos orientados hacia el espacio abierto común. Estamos ante un urbanismo pobre en cuanto a factura y materiales, y con características en planta que se corresponden ampliamente con el tipo de hábitat de organización simple descrito recientemente por C. J. Caballero ${ }^{42}$.

De esta forma, y como avanzamos anteriormente, consideramos como muy posible una primera ocupación de Los Bañales por parte de población indígena ${ }^{43}$, que se desarrollaría en la cota superior de El Pueyo y en la terraza de la ladera inmediatamente inferior.

En la segunda terraza que desciende en la ladera Este del Pueyo hacia la Ermita, encontramos un trazado urbanístico distinto con una tipología de edificación más claramente romana: casas articuladas en manzanas de viviendas a modo de insulae, con dos calles principales que se cruzan perpendicularmente. El acceso coincide con el descrito por A. Beltrán, realizándose a través de una calle enlosada que en un momento dado, con el descenso de cota de la terraza, cambia su orientación dirigiéndose hacia la zona de la Ermita.

Así, observamos un poblamiento desarrollado tanto en lo alto del cerro como en la ladera Este, fechando su posible origen en el siglo III a.C.; y una segunda fase de poblamiento de cronología específicamente romana que se desarrollaría en cotas más bajas del cerro, orientado hacia la vertiente Este del mismo.

41 Esta zona sufre, además, un gran rebaje, sirviendo la roca extraída como material de cantera para la construcción de las viviendas del poblado (CISNEROS, M.: 1986, 613-619).

42 Es un tipo de hábitat ocupacional de viviendas enfrentadas entre sí, dispuestas en planta en torno a una o dos calles paralelas, siempre desarrolladas en la parte superior de cerros y sus laderas, la fachada posterior de las casas a modo de muralla, y con un abastecimiento pluviométrico de agua, (mediante almacenamiento en depósitos, de los cuales tenemos constancia en Los Bañales), canalizaciones aprovechando pendientes, ausencia de espacios públicos cubiertos, y con un área de ocupación de entre $2000 \mathrm{~m}^{2}$ y $1 \mathrm{Ha}$. Su origen se remonta al siglo III a.C., según CABALLERO, C. J.: 2003, 132.

${ }^{43}$ Tesis que apoyamos sobre la mención a cerámica ibérica hallada en el yacimiento por GALIAY, J.: 1944, 16-17; y por el estudio de materiales realizado por C. Aguarod dentro del marco de excavaciones de A. Beltrán, que aunque no identifica cerámica indígena, sí documenta cerámica a torno de horizonte hallstático, y restos de cerámica republicana romana (AGUAROD, M. ${ }^{a}$ C.: 1975, 990). 
Dentro de esta área englobaríamos la necrópolis de la ciudad, ubicada probablemente en la ladera Sudoeste del Pueyo de Los Bañales. De ella hay documentadas una cupa y una estela con inscripciones, una de ellas aun in situ ${ }^{44}$ y la otra conservada en el Museo Provincial de Zaragoza ${ }^{45}$.

\subsection{El área monumental: el posible Foro y el posible Templo}

Una segunda zona del yacimiento estaría constituida por los restos monumentales, excluyendo de ellos las termas que consideramos aparte debido a lo conservado de sus restos. Así, nos encontramos con dos espacios separados y claramente diferenciados pero con una función pública: los denominados Templo y Foro.

Ambos son dos de los espacios aparentemente públicos del yacimiento, pero sin una función definida a falta de un estudio arqueológico de los restos. Aún así, tanto el Foro como el Templo mantienen en este artículo la denominación dada por la historiografía anterior para facilitar las labores de redacción del presente trabajo y, sencillamente, de forma convencional.

El supuesto Templo lo encontramos al Este de la ladera de El Pueyo de Los Bañales, flanqueando por el Sur la calle de acceso al poblado. De él conservamos tan sólo parte de la cimentación del pórtico y restos de la escalera de acceso al podio, siendo éste enlosado.

En cuanto al posible Foro, su ubicación guarda relación con la orientación de la fachada Este-Oeste del templo. Se encuentra emplazado en la zona Norte del yacimiento, al Nordeste de El Pueyo de Los Bañales. Lo conforman restos de un pórtico que se desarrolla a lo largo de más de 60 metros lineales dirección Este-Oeste, con una anchura entre muros de alrededor de 2 metros, y una serie de columnas marcando el espacio porticado con una media de setenta centímetros de tambor. Estas columnas se desarrollan cada 4 metros aproximadamente, quedando todavía dos en pie. El pórtico retranquea en el lado Este en ángulo recto, continuando la secuencia de peristilo durante aproximadamente 16 metros, dirección Norte-Sur.

Al Norte de esta estructura foral existen restos de cimentaciones, con una escalera que conserva doce peldaños y un descansillo labrados en roca ${ }^{46}$. Actual-

44 Vinculada, además, a noticias de a un mosaico romano (BELTRÁN LLORIS, F.: 1976, 159). La lectura de la pieza aparece documentada por GALIAY, J.: 1944, 21, junto con la mención a un número indeterminado de lápidas y estelas funerarias, noticia después recogida por LOSTAL, J: 1980, 72 y 89. Además de la cupa documentada in situ, se conocen al menos tres cupae más en el área de Los Bañales y vinculadas al yacimiento romano de La Pesquera (LASUÉN, M. ${ }^{a}$ D., y NASARRE, E: 2008 y también ANDREU, J., y JORDÁN, A.: 2003-2004, 432-433, n. ${ }^{\circ} 2$, y con valoración del conjunto completo en ANDREU, J.; JORDÁN, A.; NASARRE, E.; y LASUÉN, M.: en prensa, s. pp.

${ }^{45}$ Nombrada y ubicada vagamente por LOSTAL, J.: 1980, 89. Presenta decoración de busto de mujer y media luna sobre fondo de cupae habiendo sido revisado recientemente el texto por ANDREU, J., y JORDÁN, A.: 2003-2004, 432, n. ${ }^{\circ} 2$.

46 Escalera ya nombrada como parte integrante del conjunto foral por GALIAY, J.: 1944, 14. 


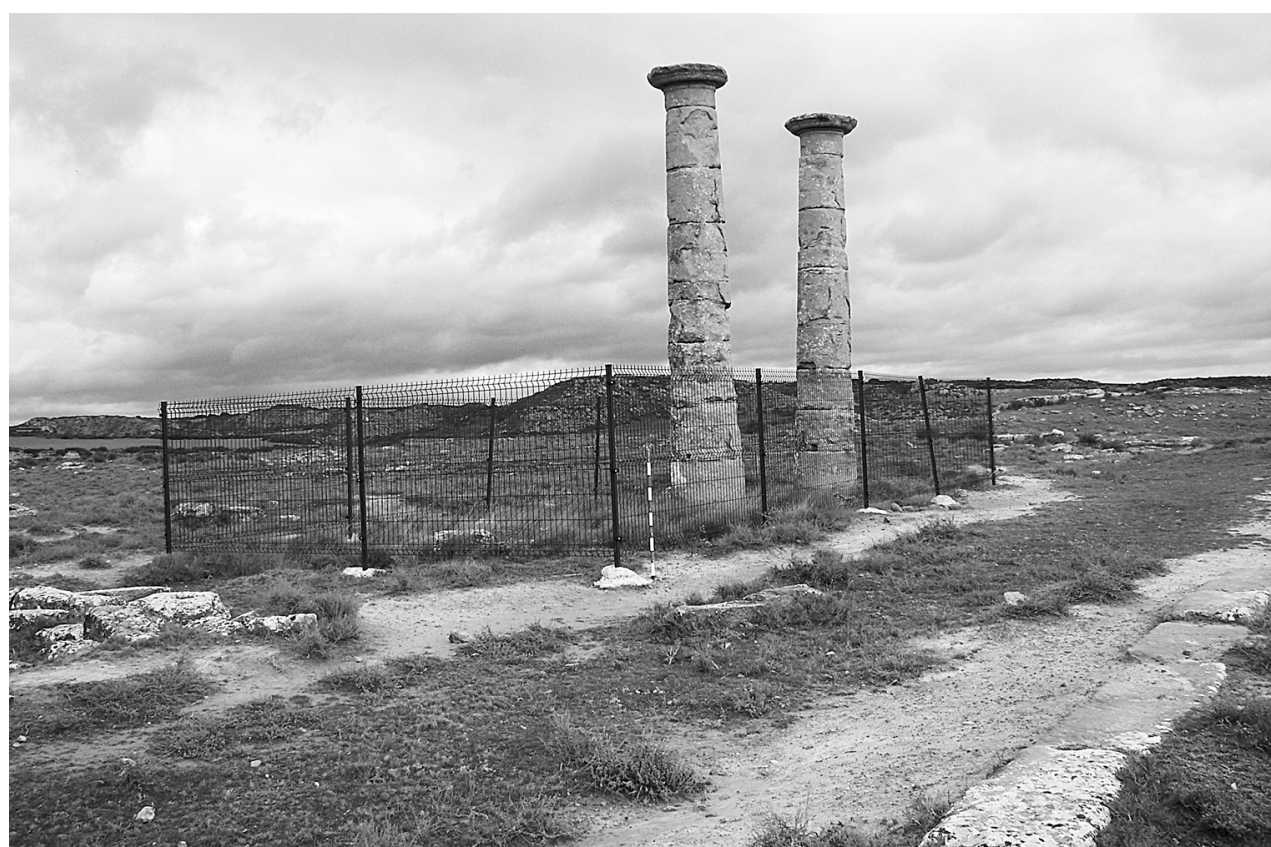

Fig. 2. Panorámica general del foro de Los Bañales.

mente continúa en vigor la hipótesis elaborada por A. Beltrán ${ }^{47}$ que identifica estos restos de cimentación junto con la escalera como parte de un conjunto de viviendas (Fig. 2).

\subsection{Las termas}

Como tercera área de estudio del yacimiento encontramos el edificio termal ${ }^{48}$, situado al Este del Pueyo de los Bañales y al Sur del Foro y la Ermita, en un desnivel del terreno que hace caer la cota alrededor de 3 metros en pendiente aproximadamente. Así, es una zona de recepción natural de aguas tanto desde el área del Foro como desde la de la Ermita.

La descripción del edificio la vamos a realizar siguiendo el itinerario termal que planteamos como más probable ${ }^{49}$. Accedemos al edificio termal desde un primer

47 BELTRÁN LLORIS, F.: 1976, 162.

48 Optamos por considerar el edificio como «recinto termal», "edificio termal», o de forma más definida, «termas», dejando así para ulteriores estudios la problemática existente a día de hoy en relación a la terminología latina de los edificios de baños romanos (KRENCKER, D., KRÜGER, E., LEHMANN, H., y WACHTLER, H.: 1929; REBUFFAT, R.: 1991; NIELSEN, I.: 1990; DÍEZ DE VELASCO, F.: 1998; GROS, P.: 1996-2001, 534-436).

49 Respecto de itinerarios semejantes veáse: AQUILUĖ, X., CASTANYER, P., SANTOS, M., y TREMOLEDA, J.: 2002; GROS, P.: 1996-2001, 434-436; REMOLÀ, J. A., y RUIZ DE ARBULO, J.: 2002, 2965 y Vitr., De Arch. 5, 10. 
vestíbulo al que se llega por el Este a través de dos escalones descendentes, enmarcados por una puerta flanqueada por pilastras adosadas al muro. Esta entrada estaría seguramente porticada ${ }^{50}$. El vestíbulo, de cerca de 4 metros de ancho por seis de largo, presenta un pavimento enlosado y un banco adosado al muro Norte colocado sobre pilares, dejando espacios huecos entre éstos.

Desde él se accede, por medio de un tramo de cinco peldaños descendentes que conforman una escalera de alrededor de 2 metros de largo, a la denominada por A. Beltrán Sala de Espera, denominación que optamos por mantener como válida. Este acceso se encuentra alineado con la puerta de entrada al vestíbulo, continuando por tanto con la orientación Este del mismo. La sala presenta 12 metros cuadrados de pavimento enlosado, con una serie de bancos adosados al muro Norte y Oeste que determinan su carácter de zona de espera. Mantienen la misma tipología de estructura elevada sobre pilares que observamos en el banco corrido del vestíbulo.

Desde esta sala se abre en la pared Sur un acceso al apodyterium cubierto por una bóveda de cañón, delimitándose así un espacio que hemos considerado a modo de acceso al apodyterium, o espacio de transición que prepara para el acceso al verdadero recinto termal ${ }^{51}$.

El apodyterium es la sala mejor conservada del recinto termal, objeto de una restauración en 1973 y 1975 cuyos resultados son: la reconstrucción del muro Sur de la estancia; el recrecimiento de la altura general de los lienzos mediante listones de madera; y la colocación de una cubierta con tejado a dos vertientes a modo de protección, reemplazando la bóveda de cañón original.

Se trata de una estancia de aproximadamente 17 metros de largo por cinco de ancho con más de 9 metros de alzado, en la que se aprecia una secuencia de loculi tallados en los muros con forma de hornacinas con arco de medio punto, a modo de consignas para los usuarios del recinto termal. El nivel de pavimento ha sido excavado, quedando la cota actual unos 30 centímetros por debajo del mismo. El apodyterium tendría con seguridad dos puertas más: la primera, ubicada en el lienzo Oeste, es un vano de 1 metro de luz con arco de medio punto que conduce a un pasillo enlosado en dirección Este-Oeste, con una canalización a nivel bajo pavimento. La segunda puerta se encuentra en el lienzo Sur de la estancia, con características similares a la primera, y que da paso al frigidarium, siguiente espacio a visitar dentro del itinerario termal.

50 Los materiales de construcción de las termas son sobre todo bloques de arenisca calcárea, extraída en una cantera de carácter estrictamente utilitario que se ubicaría en un espacio próximo al edificio termal (CISNEROS, M.: 1986, 613-619)

51 Dentro de las creencias del mundo romano existe una fuerte sacralización de todo aquello que implique tránsito, véase el cruce de un río por medio de un puente o el paso de un triclinium en una domus a un peristilum. Habitualmente estos pasos se sacralizan a través de las pinturas murales que decoran las diversas estancias; con la colocación de pequeños lararios o elementos sacros en la zona de tránsito (o templos en cada extremo del puente); o por medio de la geometría del mosaico. Así, los edificios termales de Pompeya tienen en común un mismo símbolo en el mosaico ubicado en los vanos de los accesos principales, o escenas de deidades marinas en los distintos pavimentos (DIEZ DE VELASCO, F.: 1998, 35 o ELIADE, M.: 1978-1999, 24). 
Dentro de la intervención de los años setenta se reconstruye otro vano en el lienzo Sur, igual al ya descrito, y que daría paso al tepidarium. En esta misma reconstrucción se reubican los sillares con loculi tallados, pero con orientación hacia el tepidarium en lugar de continuar la secuencia de loculi del apodyterium, en la otra cara del muro ${ }^{52}$.

Continuando la descripción del recinto termal accedemos desde el apodyterium al frigidarium ${ }^{53}$, de aproximadamente 25 metros cuadrados de superficie, con tres contrafuertes adosados en su lienzo Oeste, el más meridional de los cuales enmarca también la escalera de tres peldaños que da acceso a la piscina. Del alzado del frigidarium conservamos la primera hilada de sillares, de aproximadamente 40 centímetros de altura.

La piscina mantiene un alzado similar, con una reconstrucción actual de su trazado mediante sillares de hormigón armado. Así, la prolongación final de sus lienzos laterales y todo el muro de cierre por el Sur se encuentran cubiertos por esta protección, dejando un espacio de uso de 3 metros de largo por cinco de ancho, cuya profundidad no debía ser excesiva. A. Beltrán documenta restos de opus caementicium recubriendo los muros y el pavimento con boceles en las esquinas del espacio ${ }^{54}$. Del mismo modo, encuentra un tubo de plomo ${ }^{55}$ a modo de canalización que enlaza la piscina por el lado Oeste de su lienzo Sur con un canal perimetral de agua que rodea al edificio termal, sin quedar claro si es un conducto de entrada o de evacuación de aguas.

El acceso al tepidarium plantea un problema dentro del itinerario termal ya que no quedan restos estructurales que enlacen esta sala con el frigidarium. Así, nos encontramos con una estancia gemela al mismo, ubicada al Oeste de la sala fría y al Sur del apodyterium, que presenta una longitud parecida al frigidarium pero con una anchura ligeramente mayor, y con la característica determinante de poseer restos de hypocaustum y marcas de colocación de concammeratio en sus lienzos Norte y Oeste. Por ello deducimos que el nivel de pavimento actual no es el original del tepidarium, ya que necesariamente debía localizarse en una cota superior. Así, aceptamos la hipótesis de A. Beltrán que lo sitúa a poco más de 1 metro por encima del nivel actual ${ }^{56}$, siguiendo las marcas de cimentación de los muros. Esto explicaría la ausencia de un acceso a través del lienzo que divide frigidarium y tepidarium y que enlace ambas salas, ya que el alzado conservado no es suficiente

52 La contínua reutilización a lo largo de los siglos del recinto termal como vivienda o corral conlleva una gran modificación del mismo, hecho especialmente documentado en los vanos de acceso y ventanas del edificio. Así, el apodyterium fue dividido en dos pisos para habilitar en el superior una vivienda, lo que llevó a la apertura de una entrada de luz en el lienzo Oeste del mismo; siendo el inferior usado como corral. Posteriormente tuvo usos de corral, siendo por último empleado como huerto (LABAÑA, J. B.: 1895, GALIAY, J.: 1944, y LOSTAL, J.: 1980, 85-87

${ }^{53}$ Estancia erróneamente identificada por A. Beltrán como destructio (BELTRÁN MARTíNEZ, A.: 1977, 117.

54 Técnica usual en la construcción de los depósitos de líquidos romanos, véase, al respecto ADAM, J. P.: 1989, 257-261.

55 Hallazgo publicado en BELTRÁN MARTÍNEZ, A.: 1975.

56 BELTRÁN MARTÍNEZ, A.: 1977, 118. 
para mostrar un vano que por fuerza debía situarse casi 1 metro por encima de lo que resta de muro ${ }^{57}$.

El siguiente acceso que plantea problemas es el ya descrito de la puerta que une apodyterium con tepidarium. Otro acceso lo podríamos encontrar al Sur de la estancia, donde se observan restos de una habitación que parece corresponderse con una estancia gemela a la piscina del frigidarium ${ }^{58}$. En cualquier caso el tepidarium es un espacio con restos que documentan la existencia del hypocaustum, como son los cuatro orificios de paso de aire a nivel bajo pavimento ubicados en su lienzo Oeste ${ }^{59}$; lienzo que comparte con la siguiente sala del itinerario termal, el caldarium. Existe a su vez un vano de acceso que comunica ambas estancias, prolongado hoy día hasta el nivel actual de superficie como resultado de reformas posteriores ${ }^{60}$. El tepidarium también está comunicado mediante un pequeño orificio de paso de canalización con la estancia situada al Sur, que consideramos gemela a la piscina del frigidarium.

El caldarium es la estancia de mayor superficie de todo el recinto termal después del apodyterium, con dos áreas diferenciadas por la naturaleza de su pavimento. Así, encontramos al Norte de la habitación un enlosado de aproximadamente 2 metros de ancho (las medidas del caldarium son de 66 metros cuadrados de superficie), y que se prolonga más allá de los muros de la habitación hacia el Oeste, donde quedan restos de una canalización de fábrica con revestimiento de opus caementicium, a cota ligeramente superior, y tan ancha como el espacio enlosado al que va superpuesta.

En este espacio enlosado A. Beltrán ubica un praefurnium vinculado al caldarium y al hueco que observamos en el lienzo Este del mismo (compartido con el apodyterium), que él interpretaba como el hueco de una chimenea. Documenta además restos en el enlosado de seis apoyos de un objeto mueble ${ }^{61}$, y se basa para considerar el espacio como horno en la cota a la que encontramos el enlosado, que se correspondería con la cámara del hypocaustum. Con la documentación actual no establecemos un uso conocido para este espacio, vinculado a canalizaciones bajo cota de pavimento y al caldarium, aunque parece probable su función como piscina de agua caliente.

El resto de la estancia se encuentra excavada hasta niveles de cimentación, no quedando restos del pavimento original probablemente ubicado en una cota su-

57 En caso de verificarse como viable este paso al tepidarium desde el frigidarium, faltaría por conocerse el tipo de escalera o rampa que permitiera el acceso a la cota superior del primero. Dicha escalera podría ser de fábrica, bien de elementos metálicos o de madera.

58 Este espacio paralelo a la piscina del frigidarium resulta de difícil interpretación sin una mayor documentación arqueológica, no sólo por las zonas todavía sin excavar, sino también por la existencia de un muro de cronología posterior al edificio termal que atraviesa perpendicularmente la estancia, dificultando su comprensión.

59 Se trata de orificios de sección semicircular, seguramente para dar paso a conductos cerámicos o metálicos, de alrededor de 80 centímetros de diámetro.

60 A. Beltrán incluso llega a dudar de la ubicación del paso de tepidarium a caldarium justo en ese punto del lienzo (véase BELTRÁN MARTíNEZ, A.: 1977, 116).

61 Según su hipótesis una caldera metálica, pero que dado el encharcamiento de la zona no hemos podido corroborar (BELTRÁN MARTÍNEZ, A.: 1977, 111). 
perior. A. Beltrán ${ }^{62}$ documenta restos de pilae de la suspensura del hypocaustum como elementos más significativos de la función de la estancia. En su lienzo Sur hallamos un hueco de canalización que enlazaría con el espacio ubicado al Sur de la estancia, y del que no conservamos apenas restos que delimiten su función o articulación dentro del recorrido termal63.

En el caldarium observamos dos pasos abiertos en su muro Oeste. Por un lado accederíamos, siguiendo el eje axial marcado desde el frigidarium y el tepidarium. Desde el otro, abierto más al Norte coincidiendo con la zona enlosada, se accede a una zona excavada ${ }^{64}$ hasta nivel de cimentación, con una columna central marcando el espacio, de sección cuadrada y de 1 metro de ancho, y con la canalización de fábrica antes descrita que enlaza con el espacio enlosado del caldarium.

La camera sudatio se caracteriza por su pequeño espacio útil (4 metros de largo por 3 de ancho), y por el grosor de los muros conservados, de prácticamente 1 metro de sección. Estos condicionantes deberían ayudar a crear las condiciones ambientales propicias para un ambiente de sauna ${ }^{65}$. Su único acceso se realiza desde el caldarium, y dado que el espacio está excavado hasta nivel de cimentación, a día de hoy este paso se realiza por la canalización que une ambas salas. Otro conducto atraviesa el muro Norte de la estancia hacia el espacio sin identificar descrito en el párrafo anterior, finalizando en un pequeño depósito de planta rectangular. Una última canalización se abre en el muro Oeste del habitáculo, sin que podamos interpretar a qué espacio da acceso.

Al Oeste de la camera sudatio observamos a 2 metros de distancia un muro paralelo a la misma, con orientación Norte-Sur, de al menos 11 metros de longitud conocida. En el espacio resultante entre el espacio de sauna y este muro, y como continuación del primero, se observan restos murarios en curva realizados en opus incertum, que interpretamos como un posible praefurnium.

En la fachada Sur de la camera sudatio, y compartiendo el lienzo Este con el caldarium, se observan restos de una canalización en fábrica de características similares a la descrita al Norte de la camera sudatio, enlazando con el caldarium a nivel bajo pavimento. Así, constatamos restos similares en cuanto a factura y disposición en planta en la zona Sur del edificio, junto a un espacio enlosado a nivel de cota de pavimento original, que podría ser un pequeño pasillo de servicio ubicado entre la camera sudatio y la canalización, y paralelo a ambas. Al Sur de este conjunto de restos se encuentra la continuación hacia el Este del muro de cierre por el Sur, común a las estancias más importantes del recorrido termal: caldarium, tepidarium y frigidarium (Figs. 3 y 4 ).

62 BELTRÁN MARTÍNEZ, A.: 1977, 115.

${ }^{63}$ En este espacio, todavía no excavado en su totalidad, encontramos en la zona Este restos de dos muros tardíos que dificultan la interpretación del mismo.

64 Identificada tanto por J. Galiay como por A. Beltrán como palestra (BELTRÁN MARTíNEZ, A.: $1977,116)$. Con la documentación que poseemos en la actualidad no estamos en disposición de nombrar todavía el espacio, ni de ratificar las hipótesis de los anteriores arqueólogos.

65 Encontrando paralelos, por ejemplo, en la camera sudatio de las Termas Centrales de Pompeya, que aunque de planta circular, muestra un espesor de muros desmedido en proporción a sus dimensiones (GROS, P.: 1996-2001, 446). 
El yacimiento arqueológico de Los Bañales (Uncastillo, Zaragoza)...

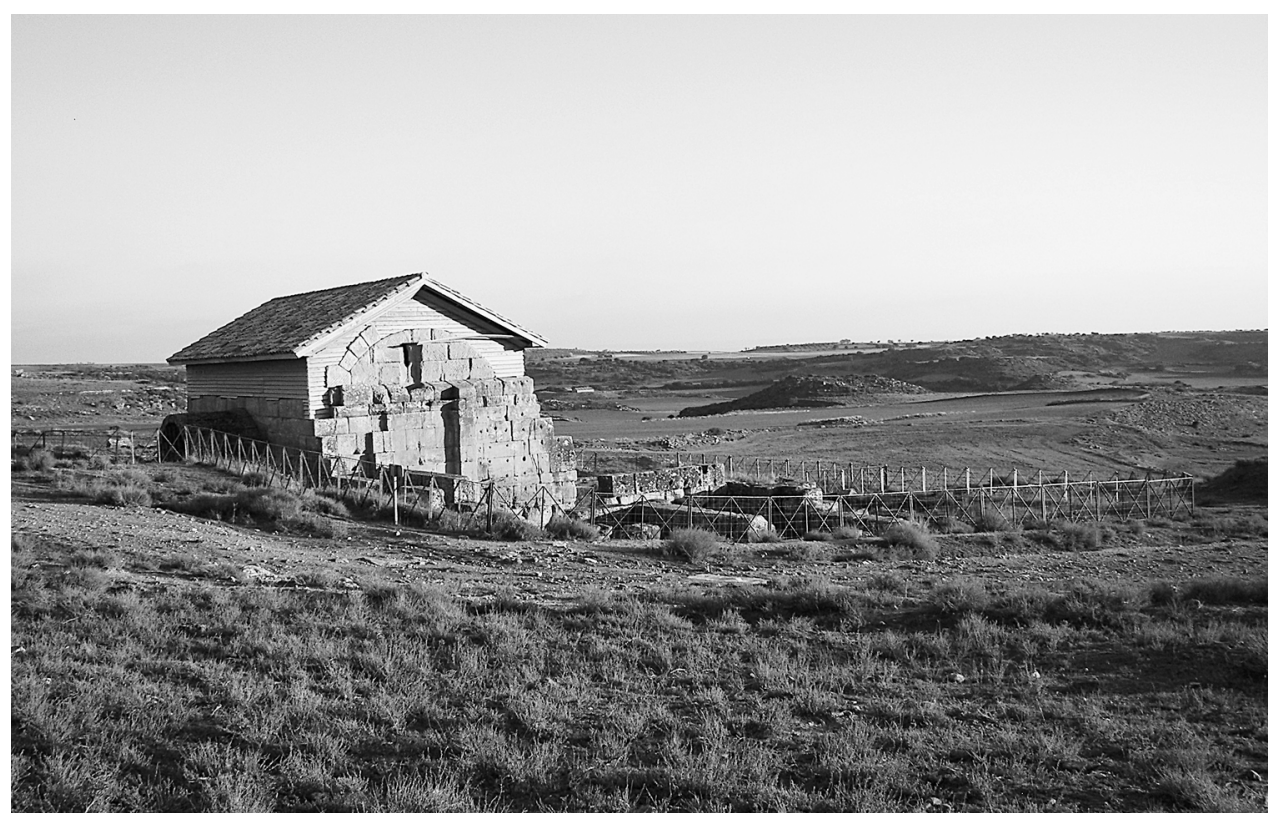

Fig. 3. Las termas del conjunto de Los Bañales.

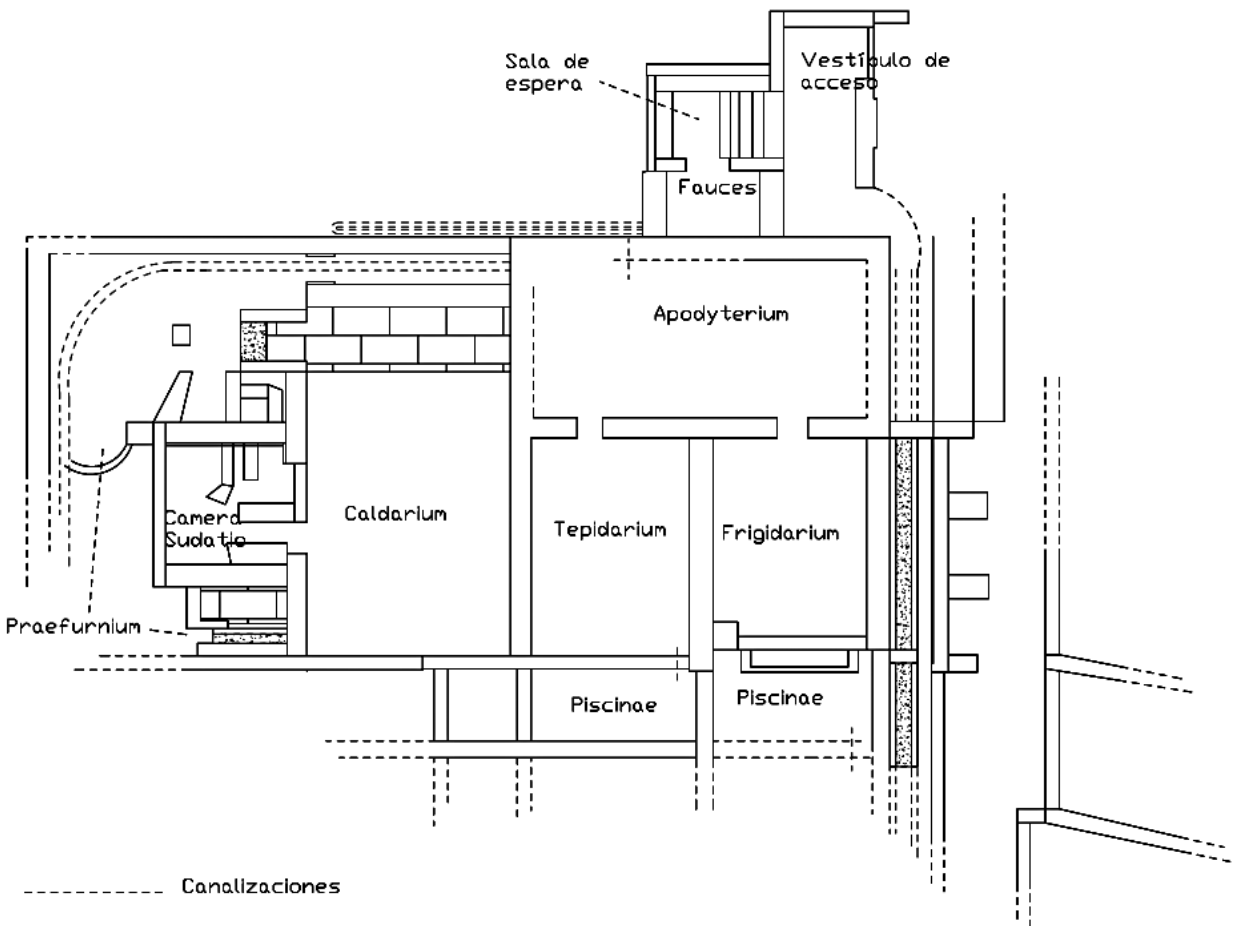

Fig. 4. Propuesta de plano de las termas de Los Bañales. 
En cuanto a las canalizaciones exteriores al recorrido termal, encontramos un canal de fábrica realizado en opus caementicium recubierto de opus signinum y opus incertum al Norte del edificio termal, y a cota de superficie. Tiene aproximadamente 11 metros de largo por 80 centímetros de ancho, y aparece en relación con el muro que se desarrolla de forma paralela en su fachada Norte; y con el sistema de recolección de aguas de las cubiertas de las salas principales del edificio, con acceso al apodyterium a través de un orificio en un loculus.

La siguiente canalización perimetral externa al edificio ya la hemos nombrado a lo largo de la descripción, y es aquella que discurre paralela al lienzo Este del edificio termal, en pendiente descendente aprovechando la topografía del terreno. Su fábrica es similar a la descrita en la canalización del párrafo precedente, con la salvedad de conservar restos del enlosado que la recubría a modo de protección, conformando así un pasillo paralelo al muro Este de las termas, flanqueado por otro muro que conserva en su fachada restos de tres sillares a modo de contrafuertes, o basas de columnas. De ello deducimos que el espacio articulado sobre la canalización iría cubierto aprovechando el cierre de las cubiertas del frigidarium.

Dicha canalización retranquea siguiendo el trazado paralelo a los muros de cierre de la fachada Sur, en dirección Este-Oeste. Así, conecta por medio de un tubo de plomo, como ya hemos descrito, con la piscina del frigidarium. Esto nos hace pensar en la posibilidad de encontrar canalizaciones parecidas que conecten con el espacio gemelo que se desarrolla al Oeste de la piscina y al Sur del tepidarium, sin interpretar todavía a falta de mayor documentación.

El mayor problema que nos presenta la interpretación de las canalizaciones es el carácter de las aguas que transportan. Parece claro que la canalización externa que encontramos al Norte del edificio en dirección Este-Oeste es de recogida de aguas $^{66}$, que distribuiría para su uso en el edificio termal, como parece indicar la cota sobreelevada de la conducción con respecto al nivel de pavimento del edificio.

No tan clara resulta la interpretación del canal perimetral que resta en el exterior del edificio. Parece conducir las aguas desde un depósito de agua sin relación directa con las termas, dado su trazado ${ }^{67}$ cubierto que no permite una alimentación pluvial y la falta aparente de una cisterna ligada en exclusiva al conjunto termal. Su trazado en ligera pendiente sin accesos conocidos hacia el frigidarium no resuelve las dudas, ya que su corriente no parece ser utilizada en fontanas dentro del mismo, ni tampoco como elemento de evacuación de letrinas ubicadas en el interior del edificio.

A su vez, su unión con la piscina se realiza desde la zona Sur de la misma lo que parece indicar, a falta de referencias de cotas, que sería un conducto de evacuación de aguas desde la piscina hacia la canalización, ayudada por el desnivel natural. Sin duda, el aprovechamiento de la corriente producida por la pen-

\footnotetext{
66 Posiblemente se nutriría de un depósito situado a cota superior, aparte de la captación de las aguas de las cubiertas del edificio.

67 Podría estar relacionado con la cisterna ubicada al Este de la Ermita, o con el posible depósito descrito con anterioridad (véase nota 25).
} 
diente dentro de la canalización podría servir como medio de evacuación de letrinas, que igual deberíamos ubicar en el pasillo antes propuesto en la cota a nivel de enlosado de cubrición del canal. Sin embargo, no contamos con datos que confirmen esta hipótesis.

Existen restos al Este del edificio termal, a unos 3 metros del mismo. Se trata de un muro de igual factura a los de las termas y misma orientación, que discurre en dirección Norte-Sur a lo largo de 12 metros aproximadamente con únicamente la primera hilada de sillares conservada, de alrededor de 80 centímetros de anchura cada uno. Presenta, además, una serie de muros tardíos y de factura pobre que lo cortan de forma transversal, paralelos entre sí, con orientación Noroeste-Sudeste que dificultan su interpretación, aunque parece estar en relación con las termas.

De esta forma vemos cómo el edificio termal presenta una zona pública de uso claramente identificada con un tipo de recorrido de planta lineal angular de recorrido retrógrado68, también llamada angular row type (vestíbulo de acceso con sala de espera-fauces-apodyterium-frigidarium-tepidarium-caldarium-camera sudatio, junto con al menos una piscina vinculada al frigidarium, y posibilidades de otra relacionada con el tepidarium), con un itinerario seguramente retrógrado, esto es, el usuario debía volver sobre sus propios pasos y hacer el recorrido termal de forma inversa, hasta la salida, estableciendo un itinerario templado-calor-frío. En cuanto al resto de dependencias descritas, parecen servir al área de servicios del edificio y de mantenimiento y funcionamiento del hypocaustum y los praefurnia, así como al sistema de abastecimiento y evacuación del sistema hidráulico (Fig. 4).

Este tipo de planta termal tiene su mayor difusión en época augústea y julioclaudia ${ }^{69}$, pudiéndose datar el edificio de Los Bañales hacia la primera mitad del siglo I d.C. ${ }^{70}$, cronología que nos muestra una construcción de las termas contemporánea a la monumentalización y romanización más profunda de la ciudad, ya que no parece pueda entenderse un edificio termal en una ciudad romanizada que no poseyera a la vez en su trazado urbanístico un foro o un templo.

El apogeo, según los materiales estudiados en intervenciones previas ${ }^{71}$, debe, pues, buscarse en el s. II, con un uso todavía prolongado de las instalaciones en el siglo III. El enclave ha aportado numerosos restos de agujas y ungüentarios ${ }^{72}$ que podrían deberse al casi seguro uso mixto de las termas; a este respecto desconocemos cualquier dato que nos permita establecer una secuencia de horarios, usos y regulaciones de las termas de Los Bañales más allá de las alusiones al respecto en las fuentes clásicas.

68 Según la clasificación esquemática de Krencker, Rebuffat y Nielsen recogida por GROS, P.: 1996-2001, 435 y después seguida para el edificio por ORTIZ, E., y PAZ, J.: 2005, 14-17 y más recientemente por ORTIZ, E.: 2006.

${ }^{69}$ GROS, P.: 1996-2001, 444-445 hace notar que en este periodo cronológico no se exporta a las provincias occidentales el primitivo laconicum circular, siguiéndose el recorrido lineal expuesto antes en recintos termales como Baetulo, o Lucus Augusti. Aún así, observamos camera sudario circulares en Gijón, los Arcos II de Clunia, o en Santa Vitoria do Ameixal.

70 Datación defendida por GROS, P.: 1996-2001, 445, con referencia directa a Los Bañales.

71 AGUAROD, C.: 1975.

72 BELTRÁN MARTÍNEZ, A.: 1977, 128-129. 


\subsection{El sistema de abastecimiento hidráulico: la presa y el acueducto}

El último espacio de estudio lo conforma el sistema de abastecimiento hidráulico de la ciudad ${ }^{73}$.

Como primer elemento nos detendremos en la caput aquae ${ }^{74}$ del sistema de abastecimiento, que ubicamos en la presa que se encuentra en una ladera a 100 metros al Noreste de Puy Foradado, cuya cabecera se orienta hacia el Sur del yacimiento. Está formada por cuatro hiladas de grandes sillares isódomos dispuestos en opus quadratum, que conforman un muro escalonado hacia el Norte con trazado en curva. Así, cierra el embalse natural de agua que se forma en la topografía del terreno al Norte del muro por medio de una pared en forma de media luna ${ }^{75}$, dispuesta de espaldas al embalse.

De ella partiría el acueducto, en canalización seguramente subterránea con una secuencia de cámaras de ventilación, en dirección Este hacia Puy Foradado. No hemos encontrado restos de dicho conducto, aunque A. Beltrán ${ }^{76}$ documenta diversos canales de derivación de aguas, que interpreta como canales de suministro directo a las villae cercanas.

El primer problema del recorrido del specus lo encontramos pues en el tramo que parte de la presa y atraviesa el cerro de Puy Foradado para enlazar con la parte de acueducto que se desarrolla sobre pilares, o acueducto elevado. Consideramos, a falta de estudios actualizados, que el specus discurre en cota superficial, incluso soterrado, y bordea por un collado adyacente la ladera Norte de Puy Foradado, descendiendo desde ahí hasta el primer pilar de la secuencia de conducto elevado.

Este tramo de estructura vertical del acueducto está conformado por una secuencia de pilares con un trazado general en curva con el centro del arco orientado hacia el norte del yacimiento. Es un diseño que busca, por medio de la curva, mantener una pendiente descendente constante, no mayor de cinco grados, que permita una corriente de agua adecuada en el specus ${ }^{77}$. Evita así un exceso de fuerza en el recorrido del agua que haga inviable el mantenimiento del sistema de abastecimiento de aguas de la ciudad.

Aprovecha además su diseño para excavar la caja de cimentación de los pilares sobre una formación de roca que se desarrolla a lo largo del trazado del acueducto vertical, y que sirve como base de cantera para la extracción de los sillares

${ }^{73}$ La principal referencia en fuentes literarias a los sistemas de abastecimiento de una ciudad romana la encontramos en Frontin., Aq., y, por supuesto, en Vitr., De Arch., 8.

${ }_{74}$ A falta de un estudio que profundice en la verdadera fons de la cual proviene el caudal que abastece al acueducto (como vimos según J. Galiay ubicada en el Arba de Luesia, según A. Beltrán en la misma ladera donde se encuentra la presa, en forma de manantial a día de hoy seco), planteamos ubicar la caput aquae en la presa de Puy Foradado.

${ }_{75}$ La presa de Puy Foradado es la única en su tipología conocida en el mundo romano de la Península lbérica, siendo el resto de presas de muros rectos, con o sin apoyo en contrafuertes. ARENILLAS, M.: 2002.

76 BELTRÁN MARTíNEZ, A.: 1977, 97.

77 Es habitual que el trazado del acueducto sobre estructura elevada sea mayor que el que recorrería si se dibujara en línea recta entre los dos puntos que une (TÖLLE-KASTENBEIN, R.: 1993-2005, 79. 
que conforman los pilares, facilitando así su construcción ${ }^{78}$. La caja de cimentación llega a tener una profundidad en algunos casos de 30 centímetros.

Los pilares conservados en la actualidad son treinta y dos ${ }^{79}$, con alturas que oscilan entre los 3 y los 9 metros. La estructura en todos ellos es similar, con una serie de sillares de arenisca ${ }^{80}$ de factura tosca e irregular superpuestos en seco con una leve lechada. No existe una medida estándar de los bloques, siendo en su mayor parte de proporciones desiguales. Sí observamos un decrecimiento del tamaño del sillar conforme aumenta la altura el pilar. El bloque inferior se encaja en la caja de cimentación excavada en roca, y el superior muestra un rebaje curvo en el que asentaría el canal del specus, seguramente de madera o metal. El sillar inmediatamente inferior tiene una perforación de sección semicircular que ha dado lugar a diversas interpretaciones, aunque muy probablemente esté relacionado con el sistema de sujeción de la canalización ${ }^{81}$.

Hay una distancia media de 4 metros de separación entre pilar y pilar con interrupciones a lo largo de la secuencia del trazado, debido a la degradación del acueducto, que nos hacen pensar en la existencia de hasta setenta y cinco pilares aproximadamente, que conducirían el specus a través de un recorrido de alrededor de 300 metros.

Así, a día de hoy conservamos, desde Puy Foradado en dirección a los restos arquitectónicos de Los Bañales, una serie de doce cajas de cimentación desde el cerro hasta el primer pilar del acueducto conservado. A partir de ahí discurren una serie de tramos del acueducto articulados en diez pilares iniciales, que recorren alrededor de 75 metros de trazado. El siguiente tramo de pilares conservados, a unos 30 metros del primero, conserva los elementos de mayor altura del acueducto, llegando a medir sus hiladas de bloques hasta 9 metros de alto, por lo que registran también un ancho del primer sillar, o basa, mayor que el resto. Encontramos un nuevo vacío de 15 metros en el trazado, continuando después la secuencia de pilares sin faltas hasta completar el número de treinta y dos (Fig. 5).

A partir de ahí el trazado del specus discurre en canales excavados en roca, seguramente soterrados y con cámaras de ventilación en origen, que pueden seguirse sin grandes problemas hasta la zona monumental de la ciudad.

El principal problema que se presenta a la investigación respecto de la llegada del trazado del acueducto a ésta es el desconocimiento que tenemos de la ubicación del castellum aquae de distribución de las aguas para el uso urbano de las mismas. Así, sólo conservamos restos de una cisterna en la fachada Este de la Er-

78 CISNEROS, M.: 1986, 613-619.

79 De los treinta y seis documentados por LABAÑA, J. B.: 1895, 18.

80 A. Beltrán documenta la misma marca de cantería y técnica de construcción en estos sillares que en los bloques de arenisca revestida de estuco de las termas, pero es un dato que falta de confirmar con un nuevo estudio arqueológico (véase BELTRÁN MARTíNEZ, A.: 1977, 105).

${ }_{81}$ Cisneros propone su uso como hueco por donde ajustar las cuerdas que asegurarían la canalización sobre el pilar (CISNEROS, M.: 1986, 614). Por el contrario, A Beltrán (BELTRÁN MARTíNEZ, A.: $1977,98)$ defiende el uso de estas perforaciones como elementos de apoyo de tirantes de madera que irían desde la perforación hasta el canal. 


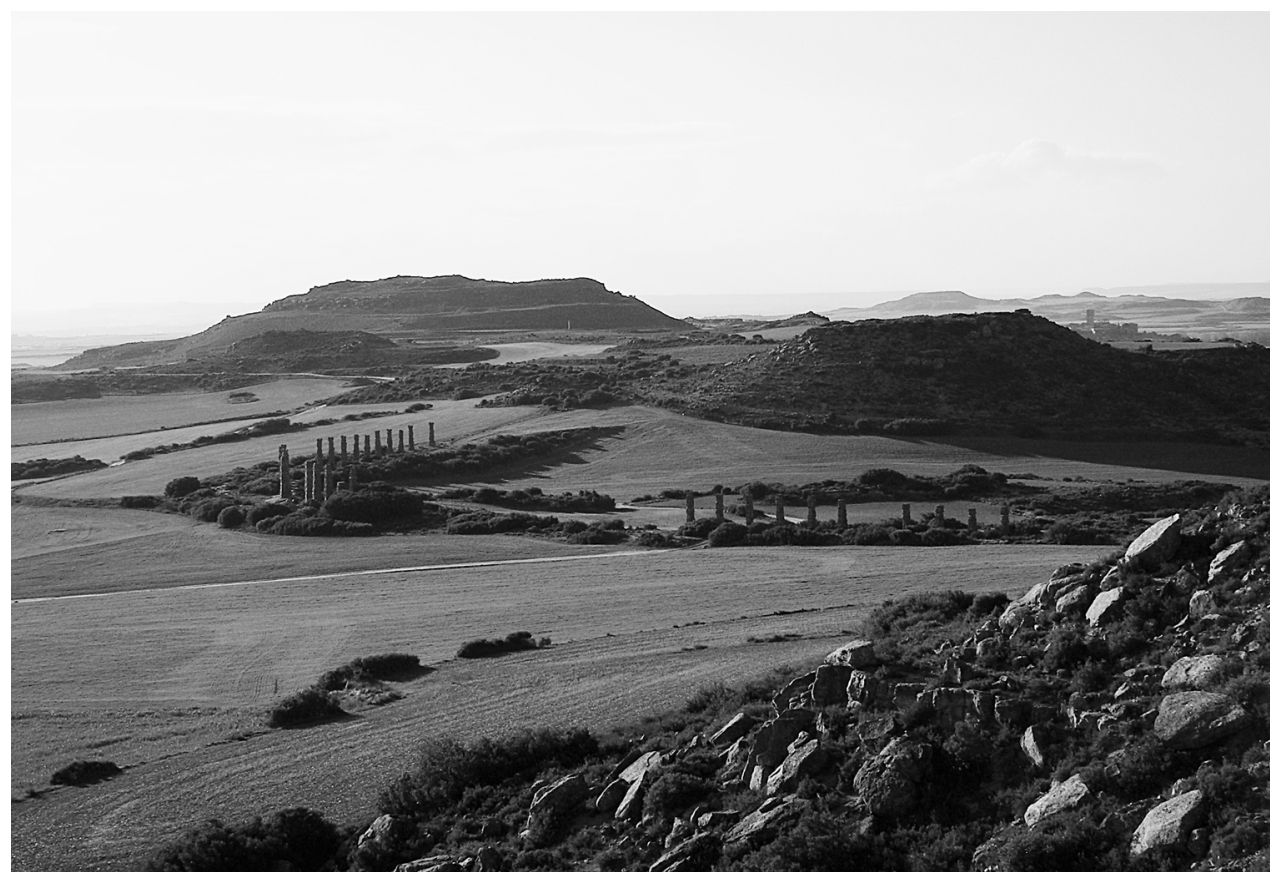

Fig. 5. El acueducto de Los Bañales.

mita, y la documentación de J. B. Labaña ${ }^{82}$ que nos indica la existencia de un segundo depósito en la cota inmediatamente superior al Norte de las termas, salvando un desnivel del terreno. En ambos casos existe un salto del terreno que sitúa la boca de alimentación de ambas cisternas en una cota bastante elevada con respecto al specus del acueducto ${ }^{83}$, constituyendo uno de los puntos a dilucidar en un futuro estudio detallado del sistema de abastecimiento de la ciudad.

\section{BIBLIOGRAFÍA}

ABADÍA, J. C. (1995): «Algunos comentarios sobre el abastecimiento de agua de Caesaraugusta», Cuadernos de Aragón, 23, pp. 5-32.

ADAM, J. P. (1989): La construcción romana. Materiales y técnicas. París.

AGUAROD, C. (1975): «Avance al estudio de la cerámica de Los Bañales», en XIV Congreso Nacional de Arqueología. Vitoria, pp. 985-992.

AGUAROD, C., y LOSTAL, J. (1982): «La vía romana de las Cinco Villas», Caesaraugusta, 55-56, pp. 167-218.

82 LABAÑA, J. B.: 1895, 19.

${ }^{83}$ BELTRÁN MARTÍNEZ, A.: 1977, 99, sostuvo la hipótesis de la existencia de un sifón que permitiría el acceso del agua del acueducto a la cisterna de la Ermita, siendo desde ahí distribuida al segundo depósito documentado por J. B. Labaña, a las termas, y a las viviendas emplazadas al Sur y al Este de la Ermita. 
ANDREU, J. (2004): “Construcción pública y municipalización en la prouincia Hispania Citerior: la época flavia», Iberia, 7, pp. 39-76.

ANDREU, J., y JORDÁN, Á. (en prensa): «Epigrafía, organización del territorio y poblamiento en territorio de Vascones: Los Bañales (Uncastillo, Zaragoza)», EFF(1), 19, s. pp.

ANDREU, J., JORDÁN, Á., NASARRE, E., y LASUÉN, M. (2008): "Cuatro cupae inéditas en territorio de Vascones (Hispania Citerior)», Aquitania, 24, pp. 123-138.

AQUILUĖ, X., CASTANYER, P., SANTOS, M., y TREMOLEDA, J. (2002): «Primers resultats del projecte d'intervenció arqueològica a les termes publiques de la ciutat romana d'Emporiae, (Empuréis, l'Escala, Alt Empordà)», Empuries, 53, pp. 241-260.

ARENILLAS, M. (2002): "Obras hidráulicas romanas en Hispania», en I Congreso sobre las Obras Públicas Romanas. Mérida (publicada en: http://traianus.rediris.es/textos/ hidraulicas.htm).

BELTRÁN MARTíNEZ, A. (1977): «Las obra hidráulicas de Los Bañales (Uncastillo, Zaragoza)», en Segovia. Simposium de arqueología romana. Barcelona, pp. 91-129.

- (1975): «El tubo de plomo del frigidarium de las termas de Los Bañales (Uncastillo, Zaragoza)", en XIV Congreso Nacional de Arqueología. Vitoria, pp. 1049-1054.

BELTRÁN LLORIS, F. (1976): «El planteamiento urbano de Los Bañales», en Simposion de Ciudades Augusteas. Zaragoza, pp.153-168.

- (1975): «Sobre las últimas excavaciones en El Pueyo de Los Bañales (Uncastillo, Zaragoza)", en XIV Congreso Nacional de Arqueología. Vitoria, pp.1055-1060.

BELTRÁN LLORIS, M. (1990): Guía de la cerámica romana. Zaragoza.

- (1985): «La Arqueología de las Cinco villas», en Actas de las I Jornadas de Estudio sobre las Cinco Villas. Ejea de los Caballeros, pp. 19-51.

- (2007): « ¿?», en Les vil.les romanes a la Tarraconense, implantació, evolució i transformació, Barcelona, pp. ¿?-¿?.

BENDALA, M., y ABAD, L. (2008): «La villa en el marco conceptual e ideológico de la ciudad tardorromana», en FERNÁNDEZ OCHOA, C., GARCÍA-ENTERO, V., y GIL, F. (eds.): Las villae tardorromanas en el Occidente del Imperio: arquitectura y función, Gijón, pp. 17-36.

BLÁZQUEZ, J. M. ${ }^{a}$ (1977): «La administración del agua en la Hispania romana», en Segovia. Simposium de arqueología romana. Barcelona, pp. 147-161.

CABALLERO, C. J. (2003): La ciudad y la romanización de Celtiberia. Zaragoza.

CASADO, M. ${ }^{a}$ P. (1975): «Yacimientos desde la Edad del Bronce a época romana, en el curso medio del río Riguel (Zaragoza)», en Miscelánea arqueológica dedicada al Profesor A. Beltrán. Zaragoza, pp. 131-149.

CISNEROS, M. (1986): «Canteras y materiales de construcción de Los Bañales (Uncastillo, Zaragoza)", en Estudios en homenaje al Dr. Antonio Beltrán Martínez. Zaragoza, pp. 613-619,

CISNEROS, M., y LA PUENTE, M. ${ }^{\text {a }}$ P. (1989): «El análisis petrológico de los morteros y su interés arqueológico». En Actas I Coloquio de Pintura Mural Romana en España. Valencia, pp. 75-80.

DÍEZ DE VELASCO, F. (1999): «El agua en el viaje de la muerte en la Grecia antigua: identidad y memoria», en La cultura del viaje. II Semana Canaria sobre el Mundo Antiguo. Madrid, pp. 15-43.

- (1998): Termalismo y religión. La sacralización del agua termal en la península Ibérica y el norte de África en el mundo antiguo. Madrid.

EGEA, A. (2002): «Ingeniería hidráulica en Cartago Nova: las tuberías de plomo». Mastia, 1, pp. 167-178,

ELIADE, M. (1979-1999): Historia de las creencias y las ideas religiosas. II. Barcelona.

ESPINOSA, U., y LÓPEZ, R. (1997): «Agua y cultura antigua en el Alto-medio Ebro», en Termalismo antiguo. Actas del I Congreso Peninsular. Arnedillo (La Rioja), Madrid, pp. 259-265.

GALIAY, J. (1949). Segunda campaña del Plan Nacional en Los Bañales (Zaragoza). Madrid. 
- (1944): Las excavaciones del Plan Nacional en Los Bañales de Sádaba (Zaragoza). Madrid.

GARCÍA Y BELLIDO, A. (1962-63): «La Villa y el Mausoleo Romanos de Sádaba», AEspA, 35-36, pp. 166-170.

GARCÍA-ENTERO, V. (2001): Los balnea de las uillae hispanorromanas: provincia Tarraconense, Madrid.

GONZÁLEZ, I., y VÁZQUEZ, A. (1993): «Estudio técnico sobre la conducción de aguas a Caesaraugusta», en El acueducto romano de Caesaragusta. Zaragoza, pp. 23-38.

GROS, P. (1996-2001): L'architettura romana. Dagli inizi del III secolo a.C. alla fine dell'alto impero. I monumento pubblici. Milán.

FERNÁNDEZ, C. (1983): Ingeniería hidráulica romana. Madrid.

- (1972): Acueductos romanos en España. Madrid.

FUENTE, M. ${ }^{a}$ J. (1999). Diccionario de historia urbana y urbanismo. Madrid.

KRENCKER, D., KRÜGER, E., LEHMANN, H., y WACHTLER, H. (1929): Die Trierer Kaiserthermen, Ausburg.

LABAÑA, J. B. (1895): Itinerario del Reino de Aragón. Zaragoza.

LABE, L. F. (1975): «Sobre una posible centuriación romana próxima a Los Bañales (Uncastillo)», en XIV Congreso Nacional de Arqueología. Vitoria, pp. 831-835.

LASUÉN, M. a D., y NASARRE, E. (2008): Plan General de Ordenación Urbana de UncastiIlo. Delimitación de yacimientos arqueológicos en parcelario rústico. Memoria entregada en D.G.A. Inédito.

LOSTAL, J. (1980): Arqueología del Aragón Romano. Zaragoza.

NIELSEN, I. (1990): Thermae et balnea. The Architectural and Cultural History of Roman Public Baths, Aarhus.

ORTIZ, E. (2006): «Los Bañales (Uncastillo). El tiempo ausente del espacio vigente. Baños Romanos», en CABELLO, J. (dir.): ArquEJEAlogía. Ejea de los Caballeros y las Cinco Villas, de la Prehistoria a la Antigüedad Tardía. Zaragoza, pp. 105-116.

ORTIZ, E., y PAZ, J. (2005): Los Bañales, Uncastillo. Los Atilios. La Sinagoga, Sádaba. Zaragoza,

PALOL, P. de (1967): Arqueología cristiana de la España Romana, Madrid.

RAMALLO, S. (ed.) (2003): La decoración arquitectónica en las ciudades romanas de Occidente, Murcia.

REMOLÀ, J. A., y RUIZ DE ARBULO, J. (2002): «L'aigua a la còlonia Tarraco», Empuries, 53, pp.29-65.

RODRÍGUEZ NEILA, J. F. (1996): Ecología en la Antigüedad Clásica. Madrid.

TÖLLE-KASTENBEIN, R. (1993-2005): Archeologia dell'acqua. La cultura idraulica nel mondo classico. Milán.

VENTURA, Á. (2000): «Los acueductos romanos de Córdoba y su rehabilitación Omeya». Empuries, 53, pp. 113-128.

- (1993): El abastecimiento de agua a la Córdoba romana. II: Acueductos, ciclo de distribución y urbanismo. Córdoba.

VV.AA. (2003): Uso y gestión del agua en Aragón. Zaragoza.

ZAPATER, M. A., y YÃÑEZ, A. (1995): Los restos arqueológicos de Los Bañales, Uncastillo (Zaragoza). Estado actual, peticiones soluciones y alternativas propuestas. Uncastillo. 